ORIGINAL ARTICLE

\title{
When is physician assisted suicide or euthanasia acceptable?
}

\author{
S Frileux, C Lelièvre, M T Muñoz Sastre, E Mullet, P C Sorum
}

See end of article for authors' affiliations

.....................

Correspondence to: Dr P Sorum, Albany Medical Center, Internal Medicine and Pediatrics, 724 Watervliet-Shaker Road, Latham, NY 12110, USA;

sorump@mail.amc.edu

Revised version received 14 November 2002 Accepted for publication 14 November 2002

\begin{abstract}
Objectives: To discover what factors affect lay people's judgments of the acceptability of physician assisted suicide and euthanasia and how these factors interact.

Design: Participants rated the acceptability of either physician assisted suicide or euthanasia for 72 patient vignettes with a five factor design-that is, all combinations of patient's age (three levels); curability of illness (two levels); degree of suffering (two levels); patient's mental status (two levels), and extent of patient's requests for the procedure (three levels).

Participants: Convenience sample of 66 young adults, 62 middle aged adults, and 66 older adults living in western France.

Main measurements: In accordance with the functional theory of cognition of N H Anderson, main effects, and interactions among patient factors and participants' characteristics were investigated by means of both graphs and ANOVA.

Results: Patient requests were the most potent determinant of acceptability. Euthanasia was generally less acceptable than physician assisted suicide, but this difference disappeared when requests were repetitive. As their own age increased, participants placed more weight on patient age as a criterion of acceptability. Conclusions: People's judgments concur with legislation to require a repetition of patients' requests for a life ending act. Younger people, who frequently are decision makers for elderly relatives, place less emphasis on patient's age itself than do older people.
\end{abstract}

\section{INTRODUCTION}

Dying has become a problem. ${ }^{12}$ Recent technological advances have transformed the act of dying by making it possible not only to alleviate pain but also to extend life. The resulting possibility of being maintained on life support for months, and in some cases for years, has engendered anxiety among elderly and non-elderly patients. Accordingly, patients and their families are more and more willing to take part in the medical decisions at the end of life. ${ }^{3}$ They, their physicians, the public, and policy makers have recently had to face several difficult questions. Should a terminally ill patient be allowed to die? Should the medical profession have the option of helping such a patient to die?

\section{Opinions about helping patients to die}

The two most controversial end of life decisions are those in which physicians actively help patients to die, by means of either physician assisted suicide or euthanasia. In physician assisted suicide, the physician provides the patient with the means to end his or her own life. In euthanasia, the physician deliberately and directly intervenes to end the patient's life; this is sometimes called "active euthanasia" to distinguish it from withholding or withdrawing treatment needed to sustain life.

The opinions about physician assisted suicide and euthanasia of members of the medical professions have been extensively examined. ${ }^{4-22}$ A survey in 1996 of physicians throughout the US found that, if it were legal, 36\% of respondents would be willing to hasten a patient's death by prescribing medication and $24 \%$ would provide a lethal injection. ${ }^{16}$ Physicians in France have been more reluctant to advocate actions by physicians to end patients' lives. ${ }^{23-25}$

Meanwhile, surveys of public opinion have shown that, in the United States, an increasing proportion of people support painless euthanasia of incurably ill patients if they and their families request it from the doctor. ${ }^{26-28}$ According to Blendon and colleagues, ${ }^{26}$ this proportion passed from $34 \%$ in 1950 to $53 \%$ in 1973 and 63\% in 1991. Public opinion surveys in other countries have documented the same trend in the Netherlands, ${ }^{29}$ Canada, ${ }^{14} 3031$ and Australia. ${ }^{32}$

End of life questions have particular relevance to the seriously ill and the elderly. Nursing home residents and other elderly people have frequently been asked if, in their current states of health and under various conditions of poorer health, they would agree to various life sustaining treatments. ${ }^{33-37}$ In the study by Cicirelli-for example, ${ }^{36}$ one of the vignettes was about a patient who was "seriously ill, kept alive by machines, tube feeding, no hope for recovery". More than $60 \%$ endorsed the decision to "refuse treatment". These studies have not, however, asked whether in these situations patients would want active, life ending interventions from their physicians. None the less, a majority of terminally ill patients surveyed in Alberta, Canada, in 1995 did favour legalising euthanasia and assisted suicide. ${ }^{14}$

Whether people's age alone affects their opinions about the acceptability of life ending actions is uncertain. ${ }^{38-40}$ Its effect is difficult to predict since age itself has a limited impact on people's fear of death ${ }^{40}{ }^{41}$ and none on their willingness to trade any time in current health for a lesser duration of perfect health. $^{42} 43$

\section{Factors influencing acceptability}

Knowing the relative impact of various factors on people's opinions about the acceptability of helping to end a patient's life would provide guidance to those who assist patients and their families in making end of life decisions-physicians, health psychologists, ${ }^{44}$ lawyers, and medical ethicists-as well as to those who make health care policy. Multiple investigators have examined these factors. ${ }^{15} 313745465748$ 
Cuperus-Bosma, van der Wal, Looman, and van der Maas ${ }^{47}$ used the most rigorous methodology. They systematically manipulated the characteristics of their patient vignettes in order to determine the relative impacts of these characteristics on the participants' judgments. They asked members of the public prosecution in Netherlands to decide whether to hold an inquest in each vignette. They examined three factors: type of suffering (pain or loss of dignity); life expectancy (short, medium, or long), and the existence of an explicit request (yes, no, not mentioned). The presence or absence of an explicit request was the strongest determinant of the prosecutors' decision, although they also took both other factors into account.

Our aims were to extend the scope and methods of Cuperus-Bosma and colleagues ${ }^{47}$ by looking at lay people and determining not only what factors are most important for them in judging the acceptability of physicians' interventions to end patients' lives, but also in what way these factors interact. We measured, to begin with, the impact of a broad spectrum of factors already shown to affect people's opinions: the patient's age; ${ }^{46}$ the level of curability of the illness; ${ }^{31} 374648$ the degree of physical suffering; ${ }^{37}{ }^{46}$ the patient's mental status; ${ }^{15} 37$ the kind of life ending procedure envisioned (euthanasia versus physician assisted suicide), ${ }^{31}{ }^{45}$ and the presence or absence of an explicit request. ${ }^{47}$ We kept constant the type of suffering, which was identified as physical rather than mental, and life expectancy, which was set at one week to one month.

We examined, in addition, how these factors interact as people integrate them in their overall judgments of acceptability. We wanted to investigate such unanswered questions as whether the effect of curability is always the same irrespective of the patient's age, or whether the effect of patient request depends on the patient's mental status or on the kind of life ending procedure envisioned. We also looked at how people's personal characteristics influence the way they form their acceptability judgments-whether, for example, the effect of request depends on the age of the participant, or whether the severity of suffering has the same effect irrespective of the participant's gender. We expected that these answers would give further guidance to health care advisers and policy makers.

Furthermore, our design-in which participants' ages ranged from 18 to 85 and patients' ages (about whom the participants were asked) varied from 35 to 60 to 85 -allowed us to study the effects of and interactions between these two age factors. This information is of particular interest because, in actual practice, decisions about ending life are typically made by younger people about older patients. ${ }^{39}$

\section{METHODS}

\section{The functional theory of cognition}

The methodology was based on the functional theory of cognition of Norman H Anderson. ${ }^{49-51}$ This methodology's primary aim is to reveal the cognitive rules used by people to integrate information when they make a judgment or decision. It assumes that people place subjective values on different pieces of information and that they combine these subjective values by means of a cognitive algebra dominated by addition, multiplication, and averaging. It studies how they do this indirectly and functionally-that is, it infers from people's judgments of the combined value of two or more stimuli (or pieces of information) the cognitive rules used to arrive at these judgments.

In Anderson's methodology, participants evaluate combinations of factors, rather than single factors. Accordingly, we presented our participants with a series of patient vignettes rather than with a questionnaire and thereby were able to simulate the way the issue would appear in real life-in the context of concrete patients with particular characteristics. Anderson's methodology requires, in addition, a complete factorial design - that is, our set of vignettes had to consist of all possible combinations of the within subjects factors. This design not only facilitates the determination of the impact of each factor on the overall judgments, but is necessary for the investigation of their interactions and of the cognitive rules participants have used in combining them. Furthermore, Anderson found that the true importance for people of each factor and the cognitive rules they employed were revealed better by stable rather than by momentary judgments of combined values. His methodology also requires, therefore, that participants become familiar with the task and with these combinations of variables in a "familiarisation" phase before they give a final set of judgments. This methodology has been widely utilised by the authors ${ }^{52-58}$ and others (as cited by Anderson). ${ }^{50}$

\section{Participants}

The participants were unpaid volunteers. They were recruited and tested by two research assistants who were psychology students trained in the techniques of functional measurement. ${ }^{49-51}$ Each research assistant contacted 150 people walking along city sidewalks, explained the study, asked them to participate, and, if they agreed, arranged where and when to administer the experiment. Of these 300, 194 (65\%) participated. All came from the same city of 200000 inhabitants in western France (Tours).

The research assistants were instructed to recruit an approximately equal number of participants among three age groups. The "young adults" consisted of 66 persons (41 women and 25 men) aged between 18 and 25 years, with a mean of 21 years and 7 months. The "middle aged adults" consisted of 62 persons ( 34 women and 28 men) aged between 34 and 50 years, with a mean of 42 years and 7 months. The "older adults" consisted of 66 persons (39 women and 27 men) aged between 51 and 77 years, with a mean of 60 years and one month.

\section{Material}

The material consisted of 72 cards containing a story of a few lines, a question, and a response scale. The stories were composed with a five within subject factor design-that is, all combinations of patient's age (three levels); curability of illness (two levels); degree of suffering (two levels); patient's mental status (two levels), and extent of patient's requests for the procedure (three levels). The quality of care (the best available) and life expectancy (one week to three months) were held constant; the suffering was specified as physical pain. Each story contained these five information items in the following order: (a) the patient's age $(35,60$, or 85 years); (b) the level of curability (or incurability) of the illness (completely incurable versus extremely difficult to cure); (c) the degree of the suffering (no pain versus extreme physical pain); (d) the patient's mental status (good mental health versus mental impairment), and; (e) the extent to which the patient requests the life ending procedure (no request, some form of request, repeated formal request). All patients were identified as " $\mathrm{Mr}^{\prime}$. The only additional information was: "He is currently receiving the best possible treatment"

Under each story were a question and a response scale. For 95 participants, the question was: "To what extent do you believe that euthanasia would be an acceptable procedure in this case?" For the remaining 99 participants, the question was: "To what extent do you believe that physician assisted suicide would be an acceptable procedure in this case?" The response scale was a $35 \mathrm{~cm}$ scale with a left hand anchor of "not acceptable at all" and a right hand anchor of 
"completely acceptable." Two examples are given in the appendix.

The cards were arranged by chance and in a different order for each participant.

\section{Procedure}

The site was a vacant classroom in the university or the private home of the adult participant. Each person was tested individually by one of the psychology students trained in Anderson's methods. The session had two phases. In the familiarisation phase, the experimenter explained to each participant what was expected-that is, that he or she was to read a certain number of stories in which a person is suffering from an illness that is incurable or extremely difficult to treat and requests or does not request the right to die, and that in each case the participant was to indicate the degree of acceptability of a decision to end the person's life. Next, each participant was presented with 36 stories taken from the complete set. The participant read each story out loud, after which the experimenter reminded him or her of the items of information the story contained. The participant then provided the requested acceptability rating. After completing the 36 ratings, the participant was allowed to compare responses and change them. In the experimental phase, the whole set of 72 stories was presented. Each participant provided ratings at his or her own pace, but was no longer allowed to compare responses nor to go back and make changes as in the familiarisation phase. In both phases, the experimenters routinely made certain that each subject, regardless of age or educational level, was able to grasp all the necessary information before making a rating.

The participants took 30-60 minutes to complete both phases. The experimental phase went quickly because they were already familiar with the task and the material. The participants knew in advance how long the experiment would last. None of them complained about the number of vignettes they were required to evaluate.

\section{Data analysis}

In accordance with Anderson's methodology, ${ }^{49}$ the data were analyzed, at the group level, by performing analysis of variance and by constructing graphs (using Statistica 5.0). The design of the analysis of variance was Scale (for euthanasia or physician assisted suicide) $\times$ age group of participant; $\times$ age of patient; $\times$ curability; $\times$ degree of suffering; $\times$ mental status of patient, and $\times$ extent of request, $2 \times 3 \times 3 \times 2 \times 2 \times 2 \times 3$. Gender, religious belief, and educational level were not introduced as factors in this design because preliminary analyses showed they had no significant effects and were not involved in significant interactions with the other factors. In light of the multiplicity of comparisons, the level of significance was set at 0.005 .

The graphs were made by plotting the mean group judgments of the acceptability of the life ending procedure associated with two of the variables. The judgment was on the $\mathrm{Y}$ axis, one of the variables was on the $\mathrm{X}$ axis, and for each value of $\mathrm{X}$, multiple points represented the different levels of the second variable combined with that one level of the first variable. Lines were drawn to connect all the points with the same level of the second variable. As Anderson and his colleagues have repeatedly demonstrated, ${ }^{50}$ the relation to each other of the lines in the graphs reveals the cognitive rule employed. For example, parallel lines indicate addition, and diverging lines (like a fan opening outward) indicate multiplication or, in some circumstances, averaging. The assumptions of the methodology and the validity of the results were to be confirmed by the consistency of the graphs (assuming such a consistency was found) - that is, by the fact that multiple lines had the same relation to each other.

\section{RESULTS}

For each of the 72 situations in the experimental phase, the distance was measured between the left anchor and each answer given by the participant on the response scale. All subsequent analyses were based on these measures of distance. The highest mean response, $30.1 \mathrm{cms}$, was still very distant from the possible maximal answer, $35 \mathrm{cms}$. There was thus no ceiling effect to complicate the interpretation of the results.

\section{Characteristics of participants}

Among the participants, 59\% were women. Sixty per cent had completed secondary education. Thirty per cent lived in a rural setting, $20 \%$ in the suburbs, and $50 \%$ in the city. Fifty four per cent indicated they were religious believers, and $46 \%$ non believers, although only $7 \%$ were churchgoers. Ten per cent said their lives had been in real danger at least once, and $12 \%$ said they had personally confronted the problem of euthanasia for someone close to them. None of these characteristics-including gender, educational level, and religious belief-had a significant main effect or interaction with the other factors.

\section{Main effects}

Four within subjects factors (out of the five within subjects factors considered in the study) had a significant effect. The older the patient $(20.21-15.03=5.18 \mathrm{cms}$ between the oldest and the youngest), the less curable the illness (19.35$15.66=3.69)$, the more the suffering $(19.14-15.88=3.26)$, and the more repetitive the request $(23.79-10.28=13.51$ for repeated requests versus none), the more acceptable did participants find physician assisted suicide or euthanasia. The four $F$ values were $F(2,376)=188.82, \quad \mathrm{p}<0.0001$; $F(1,188)=214.76, \mathrm{p}<0.0001 ; F(1,188)=188.40, \mathrm{p}<0.0001$; and $F(2,376)=579.63, \mathrm{p}<0.0001$. Patient request clearly had more impact than the other factors. Only one of the three between subjects factors had a significant effect. Responses given when the Physician assisted suicide scale was used were systematically higher than the Euthanasia scale was used $(18.88-16.13=2.75 \mathrm{cms}), F(1,188)=13.63$, $\mathrm{p}=0.003$. The age of the participant had no main effect.

\section{Interactions}

Several significant interactions were observed. Three of them involved the scale used and are shown in figure 1. In the top panel the three patient ages are on the horizontal axis, and the mean judgments of acceptability are on the vertical axis. Each curve corresponds to one of the scales, physician assisted suicide or euthanasia. The two curves are ascending; the older the patient, the more acceptable the physician assisted suicide or euthanasia. The two curves are separated; responses to the physician assisted suicide scale were higher than to the euthanasia scale. Furthermore, the two curves are not parallel. They form a fan shaped graph open to the right, for the physician assisted suicide curve is steeper than the euthanasia curve. Thus, on average, when participants considered physician assisted suicide, the impact of the patient's age was stronger than when they considered euthanasia: $F(1,376)=11.63, \mathrm{p}<0.0001$ (Figure 1$)$.

The centre panel is constructed in the same way as the top panel except that the two levels of curability of the illness are on the horizontal axis. The less curable the illness, the more acceptable the recourse to physician assisted suicide or euthanasia. The physician assisted suicide curve is again steeper than the euthanasia curve. Thus the impact of the curability of the illness was stronger when physician assisted suicide was under consideration than when euthanasia was being considered: $F(1,188)=7.29, \mathrm{p}<0.0001$. 

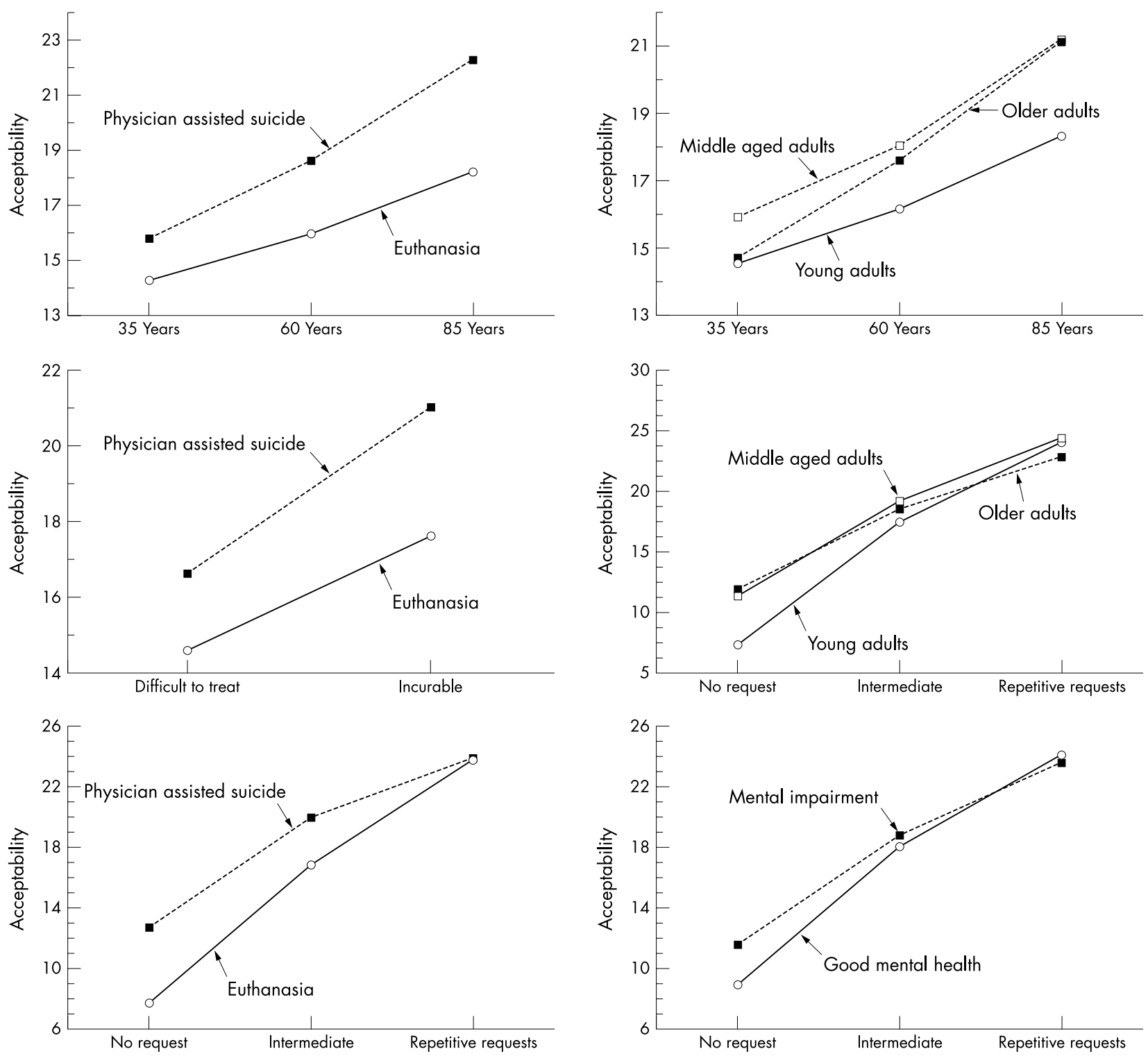

Figure 1 Effect of patient factors on judgments of the acceptability of physician assisted suicide and euthanasia: the mean judgments (in $\mathrm{cms}$ along the $35 \mathrm{~cm}$ response scale) of the acceptability of physician assisted suicide (dotted line) and euthanasia (solid line) in relation to the patient factors of age (top panel: 35,60 , or 85 years of age); degree of curability of the illness (middle panel: extremely difficult to cure or incurable), and extent of requests by the patient for the procedure (bottom panel: no request, intermediate number of requests, repetitive requests).

In the bottom panel the three levels of request are on the horizontal axis. The more repetitive the request, the more acceptable the recourse to physician assisted suicide or euthanasia. The curves form a fan shaped graph open this time to the left. The euthanasia curve is in this case steeper that the physician assisted suicide curve. When participants judged the acceptability of euthanasia, the impact of the patient's request was stronger than when they considered physician assisted suicide: $F(2,376)=18.04, \mathrm{p}<0.0001$.

Two of the interactions involved the participant's age group and are shown in figure 2 . In the top panel the three patient ages are on the horizontal axis, and the mean judgments are on the vertical axis. Each curve corresponds to one of the participants' age groups. The older the patient, the more acceptable the recourse to physician assisted suicide or

Figure 2 Effect of participants' age and patients' mental status on the judgments of the acceptability of life ending procedures: the top panel shows the mean judgments (in $\mathrm{cm}^{\prime} \mathrm{s}$ along the $35 \mathrm{~cm}$ response scale) of the acceptability of either physician assisted suicide or euthanasia of young adult participants, aged 18-25 (solid line with circles), of middleaged adults, aged 34-50 (solid line with squares), and of older adults, aged 51-77 (dotted line), in relation to the patient factor of age $(35,60$, or 85 years of age). The middle panel shows these in relation to the extent of patient requests for the life ending procedure (no request, intermediate number of requests, or repetitive requests). The bottom panel shows the judgments of acceptability for patients in good mental health (solid line) or with mental impairment (dotted line) in relation to the extent of their requests for the life ending procedure.

euthanasia. Responses given by the middle aged adults were systematically higher than responses given by the young adults. The older adults curve is steeper than the others. When older adults were judging the acceptability of physician assisted suicide or euthanasia, the patient's age had more impact than when middle aged or young adults were judging it: $F(4,376)=4.03, \mathrm{p}=0.003$ (Figure 2 ).

In the centre panel the three levels of request are on the horizontal axis. The more repetitive the request, the more acceptable the recourse to physician assisted suicide or euthanasia. The young adult curve is steeper than the others. When the young adults were judging the acceptability of 

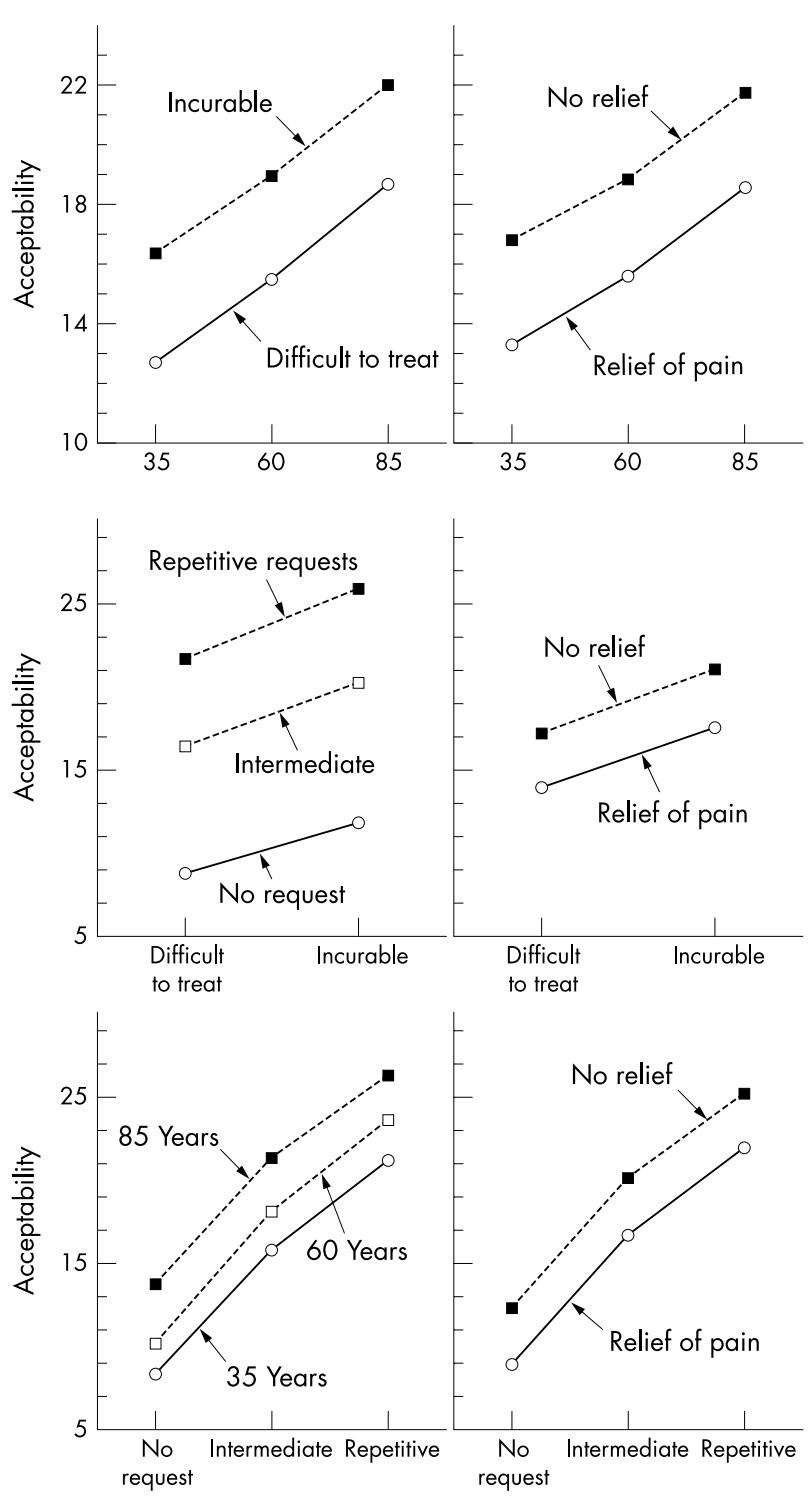

Figure 3 Interactions among patient factors in judgments of the acceptability of life ending procedures: the mean judgments (in $\mathrm{cm}^{\prime} \mathrm{s}$ along the $35 \mathrm{~cm}$ response scale) of the acceptability of either physician assisted suicide or euthanasia are shown in relation to the four within subject factors with significant main effects. The top panel shows the age of the patient $(35,60$, or 85 years of age) in relation, on the left, to the curability of the illness (difficult to treat-solid line-or incurable-dotted line) and, on the right, to the degree of physical suffering (relief of painsolid line-or no relief of pain-dotted line). The middle panel shows the curability of the illness (difficult to treat or incurable) in relation, on the left, to the extent of patient requests for the life ending procedure (no request-solid line, intermediate number of requests-dotted line with empty squares, or repetitive requests-dotted line with solid squares) and, on the right, to the degree of suffering (relief of pain - solid line-or no relief of pain-dotted line). The bottom panel shows the extent of patient requests (no request, intermediate number of requests, or repetitive requests) in relation, on the left, to the patient's age ( 35 years - solid line, 60 years-dotted line with empty squares, or 85 years-dotted line with solid squares) and, on the right, to the degree of suffering (relief of pain-solid line-or no relief of pain-dotted line).

physician assisted suicide or euthanasia, the degree of request had more impact than when middle aged or older adults were: $F(4,376)=8.56, \mathrm{p}<0.0001$.

Finally, one interaction involved only within subjects factors, as shown in the bottom panel of figure 2 . The three levels of request are on the horizontal axis. The curves correspond to the two degrees of mental impairment. They

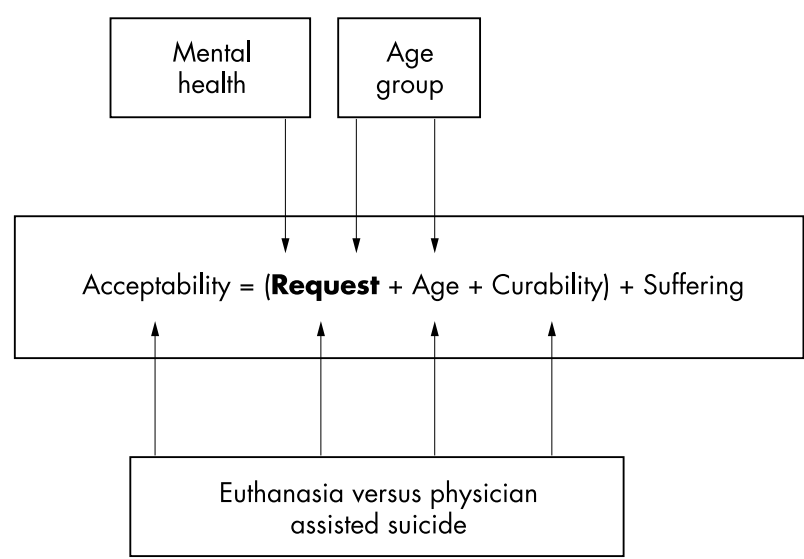

Figure 4 Model of the effects on people's judgment of the acceptability of a life ending procedure

form a fan shaped graph open to the left. When the patient in the vignette was in good mental health, the request factor had more impact on participants' judgments than when the patient was mentally impaired. The difference between the two curves is, however, restricted to the no request level. When there was no patient request, the acceptability of physician assisted suicide or euthanasia was judged higher when the patient was mentally impaired than when the patient was not impaired: $F(2,376)=39.99, \mathrm{p}<0.0001$.

Figure 3 shows the combined effect of the other within subjects factors (except for mental state, for which the main effect was small). In all cases, the pattern of results was parallelism. There was no interaction between these factors (Figure 3).

\section{DISCUSSION}

Figure 4 is a synthetic presentation of the complex set of results encountered in the study. People's judgment of the acceptability of physician assisted suicide or euthanasia appeared to depend mainly and additively on four of the five factors we examined: the level of patient suffering in spite of treatment; the extent to which the patient requested the life ending procedure; the age of the patient, and the degree of curability of the illness. These results are consistent with the findings of previous investigators. ${ }^{15} 46478$ The patient's mental status had no direct effect. Its only effect was that, in the case of no request, the level of acceptability was slightly higher when the patient was mentally impaired, regardless of the other elements in the situation and the participant's characteristics.

The variation introduced in the judgment task (euthanasia versus physician assisted suicide) and the age of the participants did not alter the basic cognitive additive schema just described. Both factors exerted their effects mainly by modifying the impact of the situational factors. Older adults placed more importance than middle aged adults on the patient's age, and middle aged adults placed more importance on it than did young adults. By contrast, older adults placed less importance than the middle aged on the number of patient requests, and the middle aged less than young adults. It appears, therefore, that, in judging the acceptability of procedures to end life, people may attach more importance to their age, and less importance to their own wishes, in proportion to the number of years they have already lived. Clearly older adults' judgments of the acceptability of life ending procedures need further study.

People judged euthanasia as less acceptable than physician assisted suicide. This was already shown by $\mathrm{Ho}^{45}$ (although 
this was in contrast to Singer and colleagues). ${ }^{31}$ The people attached greater importance to the patient's age and to the curability level of the illness when considering physician assisted suicide than when considering euthanasia. The differences between the two procedures were maximal when the patient did not request a life ending act, but disappeared when the patient requested it repetitively. The likely explanation is that physician assisted suicide implies, by definition, that the patient him or herself wills and performs the life ending act and can, until the ultimate moment, refrain from performing it. These differences thus reflect the fact that the participants correctly interpreted the distinction between euthanasia and physician assisted suicide. ${ }^{28}$

The experimental task imposed several limitations. It involved vignettes and hypothetical judgments, not real life patients and actual decisions. The information available to the participants was, therefore, restricted to a few dimensions; they could not deepen their understanding by asking further questions about the patients. In addition, we could not study all the known or presumed influences on the acceptability of a physician's intervention to help a patient die; we are currently measuring the relative importance of the factors of life expectancy and requests by the patient's family. Although participants could ask questions about the task during the phase of familiarisation, we are not certain that they all shared, in particular, the assumed interpretation of the question about physician assisted suicide when the patient had not expressed a wish to resort to it-namely, that the physician, unasked, offered to provide the means. People were asked to rate acceptability on a continuous scale, whereas in reality the decision for an individual patient or the policy for a group of patients would need to specify yes or no.

Our findings are also, of course, limited by the nature of our sample. It was a convenience sample of moderate size and restricted to the inhabitants of a small city in France. The methodology of in depth study of the way participants combined information precluded the recruitment of a large sample. Although we do not expect French people to differ greatly from those of other Western countries in the way they integrate information about life ending decisions, Braun and colleagues $^{59}$ have demonstrated that ethnicity affects the relative importance given to different attitude factors. In addition, although in order to be recruited and participate, the participants had to be ambulatory, willing to participate, and able to perform the task, we did not screen them for known terminal disease, for early dementia, or for depression. Since depressed patients are more likely to favour euthanasia and physician assisted suicide, ${ }^{60-62}$ it is likely that depressed members of the public would do the same. Finally, we did not have enough participants to search for differences between the younger and older members of the "older adults" category (ages 51-77). The nature of the sample prevents us, therefore, from attempting to generalise our findings widely.

None the less, by including in the design the ages of both patients and decision makers and by extending these ages to include both older adults and young adults, we derived lessons that, while tentative, are important for advisers of patients and their families and for formulators of health policy. Medical practitioners, health psychologists, health care lawyers, and medical ethicists will know better what issues they must be sure to discuss with patients and families, and policy makers will know better what factors must be addressed in guidelines, rules, and laws. They will know, in particular, that the key factor for lay persons, especially for younger persons, in judging the acceptability of an action by a physician to help a patient to die is a repeated request for it by the patient and that the age of the patient is less important to them than this request. This finding supports the inclusion in proposed and enacted legislation to legalise physician assisted suicide of several documented assertions by the patient over time of a desire to terminate his or her life. ${ }^{63}{ }^{64}$

\section{Authors' affiliations \\ S Frileux, M T Muñoz Sastre, Centre for Research in Psychopathology, Mirail University, Toulouse, France \\ C Lelièvre, E Mullet, Ecole Pratique des Hautes Etudes, Paris, France \\ P C Sorum, Departments of Medicine and Pediatrics, Albany Medical \\ College, Albany, NY, USA}

Portions of this paper were presented at the 25th annual meeting of the Society of General Internal Medicine on May 3, 2002, in Atlanta, GA, USA.

\section{APPENDIX}

\section{EXAMPLES OF VIGNETTES}

Mr Durand is $\mathbf{3 5}$ years old.

He has a serious illness, difficult to treat given current knowledge.

He is currently receiving the best possible treatment.

He suffers atrociously; only an appropriate pain medication

can relieve his suffering.

He is mentally impaired.

He has never expressed a wish to resort to euthanasia or physician assisted suicide.

To what extent do you think that euthanasia is an acceptable solution in this case?

Not at all acceptable - Completely acceptable

Mr Dupuis is $\mathbf{8 5}$ years old.

He has a serious illness, totally incurable given current knowledge.

He is currently receiving the best possible treatment.

He suffers atrociously; pain medication cannot relieve his suffering.

He is in good mental health.

He has asked clearly and repeatedly to resort to euthanasia or physician assisted suicide.

To what extent do you think that physician assisted suicide is an acceptable solution in this case?

Not at all acceptable - Completely acceptable

\section{REFERENCES}

1 Kastenbaum R. Death, society, and human experience, [5th ed]. Boston: Allyn \& Bacon, 1995

2 Callahan D. Death and the research imperative. N Engl J Med 2000;342:654-6.

3 Weir RF. Physician assisted suicide. Bloomington and Indianapolis: Indiana University Press, 1997.

4 Kuhse $\mathrm{H}$, Singer $\mathrm{P}$. Doctors' practices and attitudes regarding voluntary euthanasia. Med J Aust 1988;148:623-6.

5 Baum P, O'Malley E. Euthanasia: attitudes and practices of medical practitioners. Med J Aust 1990;161:137-44.

6 Kuhse $H$, Singer P. Euthanasia: a survey of nurses' attitudes and practices. Australian Nursing Journal 1992;21:21-2.

7 Shuman C R, Fournet GP, Zelhart PF, et al. Attitudes of registered nurses toward euthanasia. Death Stud 1992;16:1-15.

8 Watts DT, Howell T, Priefer BA. Geriatricians' attitudes toward assisted suicide of dementia patients. Journal of the American Gerontological Society 1992:40:878-85.

9 Kuhse H, Singer P. Voluntary euthanasia and the nurses: an Australian survey. International Journal of Nursing Science 1993:30:311-22.

10 Cohen J S, Fihn SD, Boyko EJ, et al. Attitudes towards assisted suicide and euthanasia among physicians in Washington State. N Engl J Med 1994;331:89-94.

11 Richardson DS. Oncology nurses' attitudes toward the legalisation of voluntary active euthanasia. Cancer Nurs 1994:17:348-54.

12 Stevens C, Hassan R. Nurses and the management of death, dying and euthanasia. Med Law 1994;13:541-54.

13 Aranda S, O'Connor M. Euthanasia, nursing and care of the dying: rethinking. Australian Nursing Journal 1995;3:18-21. 
14 Suarez-Almazor ME, Belzille M, Bruera E. Euthanasia and physician assisted suicide: a comparative survey of physicians, terminally ill cancer patients, and the general population. J Clin Oncol 1997;15:418-27.

15 Dickinson GE, Lancaster CJ, Sumner ED, et al. Attitudes toward assisted suicide and euthanasia among physicians in South Carolina and Washington. Omega: Journal of Death and Dying 1998;36:201-18.

16 Meier DE, Emmons C-A, Wallenstein S, et al. National survey of physician assisted suicide and euthanasia in the United States. N Engl J Med 1998:338:1193-201.

17 Vincent J-L. Forgoing life support in western European intensive care units: the results of an ethical questionnaire. Crit Care Med 1999;27:1626-33.

18 Emanuel EJ, Fairclough D, Clarridge BC, et al. Attitudes and practices of U.S. oncologists regarding euthanasia and physician assisted suicide. Ann Intern Med 2000; 133:527-32.

19 Willems DL, Daniels ER, van der Wal G, et al. Attitudes and practices concerning the end of life: A comparison between physicians from the United States and from the Netherlands. Arch Intern Med 2000;160:63-8.

20 Hanlon TRG, Weiss MC, Rees J. British community pharmacists' views of physician assisted suicide (PAS). J Med Ethics 2000;26:363-9.

21 Whitney SN, Brown BW, Brody H, et al. Views of United States physicians and members of the American Medical Association House of Delegates on physician assisted suicide. J Gen Intern Med 2001;16:290-6.

22 Asai A, Ohnishi M, Nagata SK, et al. Doctors' and nurses' attitudes towards and experiences of voluntary euthanasia: survey of members of the Japanese Association of Palliative Medicine. J Med Ethics 2001;27:324-30.

23 Glorion B. Y a-t-il une déontologie de l'accompagnement des personnes en fin de vie? Bulletin de l'Académie Nationale de Médecine 1999;183:905-9.

24 Michaud J. Faut-il légiférer sur l'euthanasie? Bulletin de l'Académie Nationale de Médecine 1999;183:911-17.

25 Abriven M, Chardot C, Fresco R. Euthanasie: alternatives et controverses. Paris: Presses de la Renaissance, 2000

26 Blendon R J, Szalay US, Knox RA. Should physicians aid their patients in dying? The public perspective. JAMA 1992;267:2658-62.

27 Caddell DP, Newton RR. Euthanasia: American attitudes toward the physician's role. Soc Sci Med 1995;40:1671-81.

28 Rogers JR. Assessing right to die attitudes: a conceptually guided measurement model. J Soc Issues 1996:52:63-84.

29 Van der Maas PJ, Pijnenborg L, van Delden JJM. Changes in Dutch opinions on active euthanasia, 1966 through 1991. JAMA 1995;273:1411-14.

30 Genuis SJ, Genuis SK, Chang WC. Public attitudes toward the right to die. CMAJ 1994; 150:701-8.

31 Singer PA, Choudhry S, Armstrong J, et al. Public opinion regarding end-oflife decisions: influence of prognosis, practice and process. Soc Sci Med 1995;41:1517-21.

32 Steinberg MA, Najman JM, Cartwright CM, et al. End of life decision making: community and medical practitioners' perspectives. Med J Aust 1997; 166:131-5

33 Michelson C, Mulvihill M, Hsu M, et al. Eliciting medical care preferences from nursing home residents. Gerontologist 1991;31:358-63.

34 O'Brien LA, Siegert EA, Grisso JA, et al. Tube feeding preferences among nursing home residents. J Gen Intern Med 1997;12:364-71.

35 Berger JT, Majerovitz D. Stability of preferences for treatment among nursing home residents. Gerontologist 1998;38:217-23.

36 Cicirelli VG. Views of elderly people concerning end of life decisions. J Appl Gerontol 1998;17:186-203.

37 Coppola KM, Bookwala J, Ditto PH, et al. Adults' preferences for life sustaining treatments: the role of impairment, prognosis, and pain. Death Stud 1999;23:17-634

38 Seidlitz L, Duberstein PR, Cox C, et al. Attitudes of older people toward suicide and assisted suicide: an analysis of Gallup poll findings. J Am Geriatr Soc 1995:43:993-8.

39 Koenig HG, Wildman-Hanlon D, Schmader K. Attitudes of elderly patients and their families toward physician assisted suicide. Arch Intern Med $1996 ; 156: 2240-48$
40 Ward RA. Age and acceptance of euthanasia. J Gerontol 1980;35:421-31.

41 Cicirelli VG. Personality and demographic factors in older adults' fear of death. Gerontologist 1999;39:569-79.

42 Tsevat J, Dawson NV, Wu AW, et al, for the HELP investigators. Health values of hospitalised patients 80 years or older. JAMA 1998;279:371-5.

43 Sherbourne CD, Keeler E, Unhtzer J, et al. Relationship between age and patients' current health state preferences. Gerontologist 1999;39:271-8.

44 Sears SR, Stanton AL. Physician assisted dying: review of issues and roles for health psychologists. Health Psychol 2001;20:302-10.

45 Ho R. Assessing attitudes toward euthanasia: an analysis of the subcategorical approach to right to die issues. Pers Individ Diff 1998;25:719-34.

46 Van Holsteyn J, Trappenberg M. Citizens' opinions on new forms of euthanasia: a report from the Netherlands. Patient Educ Couns 1998;35:63-73.

47 Cuperus-Bosma JM, van der Wal G, Looman CWN, et al. Assessment of physician assisted death by members of the public prosecution in the Netherlands. J Med Ethics 1999;25:8-15.

48 Kitchener B, Jorm AF. Conditions required for a law on active voluntary euthanasia: a survey of nurses' opinions in the Australian Capital Territory. J Med Ethics 1999:25:25-30.

49 Anderson NH. Foundations of information integration theory. New York: Academic Press, 1981.

50 Anderson NH. A functional theory of cognition. Mahwah, NJ: Lawrence Erlbaum Associates, 1996

51 Anderson NH. Empirical directions in design and analysis. Mahwah, NJ: Lawrence Erlbaum Associates, 2001

52 Muñoz Sastre MT, Mullet E, Sorum P. Relationship between cigarette dose and perceived risk of dying. Prev Med 1999;28:566-71.

53 Muñoz Sastre MT, Mullet E, Sorum P. Self assessment of inebriation from external indices. Addictive Behaviors 2000;25:663-81

54 Simeone A, Hermand D, Mullet E. Judging the probability of being infected through sexual contact. Risk: Health, Safety and Environment 2001; 12:255-80.

55 Sorum PC, Muñoz Sastre MT, Mullet E, et al. Eliciting patient disutilities for the adverse outcomes of cardiopulmonary resuscitation. Resuscitation 2001;48:265-73.

56 Bonnin-Scaon S, Lafon P, Chasseigne G, et al. Learning the relationship between smoking, drinking alcohol, and the risk of oesophageal cancer. Health Educ Res 2002;17:415-24.

57 Guillet L, Hermand D, Mullet E. Cognitive processes involved in the appraisal of stress. Stress and Health 2002;18:91-102.

58 Fourquereau E, Fernandez A, Mullet E. Stress and the urge to drink. Addict Behav 2003;28:669-85.

59 Braun KL, Tanji VM, Heck R. Support for physician assisted suicide: exploring the impact of ethnicity and attitudes toward planning for death. Gerontologist 2001;41:51-60.

60 Wilson KG, Scott JF, Graham ID, et al. Attitudes of terminally ill patients toward euthanasia and physician assisted suicide. Arch Intern Med 2000; 160:2454-60.

61 Blank K, Robison J, Doherty E, et al. Life sustaining treatment and assisted death choices in depressed older patients. J Am Geriatr Soc 2001;49:153-61

62 Blank K, Robison J, Prigerson H, et al. Instability of attitudes about euthanasia and physician assisted suicide in depressed older hospitalised patients. Gen Hosp Psych $2001 ; 23: 326-32$

63 Quill TE, Cassel CK, Meier DE. Care of the hopelessly ill: potential clinical criteria for physician assisted suicide. N Engl J Med 1992;327:1380-4.

64 Caplan AL, Snyder L, Faber-Langendoen K, for the University of Pennsylvania Center for Bioethics Assisted Suicide Consensus Panel. The role of guidelines in the practice of physician assisted suicide. Ann Intern Med 2000; 132:476-81. 